\title{
Time to blood culture positivity as a predictor of clinical outcome in patients with Candida albicans bloodstream infection
}

\author{
Cintia Zoya Nunes ${ }^{1}$, Alexandre R Marra ${ }^{1,2^{*}}$, Michael B Edmond ${ }^{3}$, Elivane da Silva Victor ${ }^{2}$ \\ and Carlos Alberto Pires Pereira ${ }^{\top}$
}

\begin{abstract}
Background: Few studies have assessed the time to blood culture positivity as a predictor of clinical outcome in fungal bloodstream infections (BSIs). The purpose of this study was to evaluate the time to positivity (TTP) of blood cultures in patients with Candida albicans BSIs and to assess its impact on clinical outcome.

Methods: A historical cohort study with 89 adults patients with C. albicans BSIs. TTP was defined as the time between the start of incubation and the time that the automated alert signal indicating growth in the culture bottle sounded.

Results: Patients with BSIs and TTPs of culture of $\leq 36 \mathrm{~h}(n=39)$ and $>36 \mathrm{~h}(n=50)$ were compared. Septic shock occurred in $46.2 \%$ of patients with TTPs of $\leq 36 \mathrm{~h}$ and in $40.0 \%$ of patients with TTP of $>36 \mathrm{~h}$ ( $p=0.56$ ). A central venous catheter source was more common with a BSI TTP of $\leq 36 \mathrm{~h}(\mathrm{p}=0.04)$. Univariate analyis revealed that APACHE II score $\geq 20$ at BSI onset, the development of at least one organ system failure (respiratory, cardiovascular, renal, hematologic, or hepatic), SOFA at BSI onset, SAPS II at BSI onset, and time to positivity were associated with death. By using logistic regression analysis, the only independent predictor of death was time to positivity (1.04; $95 \% \mathrm{Cl}, 1.0-1.1, \mathrm{p}=0.035)$, with the chance of the patient with C. albicans BSI dying increasing $4.0 \%$ every hour prior to culture positivity.
\end{abstract}

Conclusion: A longer time to positivity was associated with a higher mortality for Candida albicans BSIs; therefore, initiating empiric treatment with antifungals may improve outcomes.

Keywords: Candida, Bloodstream infection, Time to positivity, Antifungal therapy

\section{Background}

Candidemia is a serious problem in tertiary hospitals all over the world [1-3]. Despite a relatively low incidence, it is associated with higher rates of morbidity and mortality [1-3].

The use of automated systems for blood cultures was one of the great advances in the diagnosis of candidemia $[4,5]$. This method offers improved sensitivity, which is estimated to be approximately $70 \%$ [5]. Currently, it appears

\footnotetext{
* Correspondence: alexandre.marra@einstein.br

'Infectious Diseases Division, Universidade Federal de São Paulo (UNIFESP),

São Paulo, Brazil

${ }^{2}$ Division of Medical Practice, Hospital Israelita Albert Einstein, São Paulo, Brazil

Full list of author information is available at the end of the article
}

that the number of these infections has stabilized, although their mortality remains unchanged [1-3,5].

Candida albicans is still the primary cause of these infections, representing on average half of the cases $[1,6]$. The increase in non-albicans species, carries therapeutic implications because the pattern of susceptibility to azoles is species-specific $[3,6]$.

As with all infectious processes, rapid diagnosis of fungal infection combined with appropriate treatment reduces early mortality [5-7]. Blood cultures, still considered the gold standard in the diagnosis of these infections, can take days to turn positive and even longer to identify the species $[5,6,8]$.

Time to blood culture positivity (TTP) has recently been used diagnostically and prognostically for bacteremia

\section{Ciomed Central}

(c) 2013 Nunes et al.; licensee BioMed Central Ltd. This is an open access article distributed under the terms of the Creative Commons Attribution License (http://creativecommons.org/licenses/by/2.0), which permits unrestricted use, distribution, and reproduction in any medium, provided the original work is properly cited. 
[9-11]. Given the paucity of data on TTP in BSI by Candida species, the present study aims at better understanding it and its impact on clinical outcome.

\section{Methods \\ Setting}

Hospital São Paulo, at the Universidade Federal de São Paulo is a 700-bed tertiary-care facility in São Paulo, Brazil. The hospital houses four intensive care units (ICUs), including a pediatric ICU. This study was approved by the Ethics Committee of the Universidade Federal de São Paulo.

\section{Study design}

Patients with BSIs from 1 January 2002 through 31 July 2009 were identified retrospectively by use of the electronic medical microbiology record. For each case, the time to blood culture positivity was retrieved from the hospital's automated blood culture instrument. The medical microbiology record identified the patient by medical record number so that a retrospective chart review could be conducted. Patients were considered to have had a BSI due to Candida spp if one or more blood cultures were positive for this organism. Each patient was included only once, at the time of the first BSI. Patients less than 18 years old, those with polymicrobial infections, and those receiving antifungal therapy at the time of the BSI were excluded from the analysis.

Data collected included age; gender; location of the patient (ward versus ICU); the duration of hospitalization prior to the onset of the BSI; the presence of predisposing clinical factors, including neutropenia (defined as an absolute neutrophil count of $<500 / \mu \mathrm{l})$; the use of peritoneal dialysis or hemodialysis; and the presence of central venous catheters. The sources of secondary BSIs were identified by cultures of samples obtained from the primary site of infection that yielded the same pathogen. Adverse outcomes (organ failure and in-hospital mortality) occurring during the course of hospitalization were recorded.

The severity of the underlying disease preceding the positive blood culture was classified by use of the Charlson weighted comorbidity índex [12]. The patient's physiological condition on the day of the BSI was assessed by using the APACHE II score [13], SAPS II [14] and the SOFA score [15]. At the onset of the BSI, the clinical condition of each patient was classified as systemic inflammatory response syndrome (SIRS), sepsis, severe sepsis, or septic shock using criteria previously published by the American College of Chest Physicians/Society of Critical Care Medicine [16]. SIRS was defined as two or more of the following: (i) a temperature of $>38^{\circ} \mathrm{C}$ or $<36^{\circ} \mathrm{C}$, (ii) a heart rate of $>90$ beats per minute, (iii) a respiratory rate of $>20$ breaths per minute or a partial arterial $\mathrm{CO}_{2}$ pressure of $<32 \mathrm{~mm} \mathrm{Hg}$, or (iv) a white blood cell count of $>12 \times 10^{9} /$ liter or $<4 \times 10^{9} /$ liter or the presence of more than $10 \%$ immature neutrophils.

Severe sepsis was defined as organ dysfunction, hypotension, or systemic manifestations of hypoperfusion. Septic shock was defined as sepsis associated with hypotension unresponsive to intravenous fluid challenge or the need for treatment with a vasopressor agent. The presence of organ system failure at the time of the BSI and during the clinical course was assessed by using the criteria described by Fagon et al. [17]. Nosocomial infection was defined as an infection that occurred $>48 \mathrm{~h}$ after hospital admission, an infection that occurred $<48 \mathrm{~h}$ after admission to the hospital for patients who had been hospitalized in the 3 weeks prior to the admission, or an infection that occurred $<48 \mathrm{~h}$ after admission to the hospital for patients who had been transferred from another hospital or nursing home [18]. The sources of infection were also defined according to Centers for Disease Control and Prevention criteria [18]. Time to positivity was defined as the time between the start of incubation and the time to sounding of the alert signal on the automated blood culture instrument. Adequate empirical antifungal treatment was defined as therapy that was administered within $24 \mathrm{~h}$ after samples for blood culture were obtained that included any antifungal agent to which Candida albicans was susceptible [6].

\section{Microbiological methods}

Blood cultures were processed by the institution's clinical laboratory using the BACTEC ${ }^{\circledR} 9240$ blood culture instrument (Becton Dickinson, Maryland, EUA). Each blood culture set consisted of an FA aerobic bottle and an SN anaerobic bottle. All the samples of blood cultures were collected and submitted in a timely manner to the microbiology laboratory. All cultures were obtained via peripheral venipuncture and at least two bottles were obtained for each patient. The bottles were loaded into the instrument ( $24 \mathrm{~h}$ a day, 7 days a week) without delay at any time of the day. The time to positivity of the first bottle in a set to be flagged as positive was used to determine the time to positivity and was obtained by using the system's software.

The confirmation of the species was performed by screening for C. albicans using CHROMagar Candida ${ }^{\circledR}$ (CHROMagar Microbiology, Paris, France). Samples of non-albicans Candida were identified by biochemical profile, the manual method ID $32 \mathrm{C}^{\circledR}$ (BioMérieux, Marcy-1 'Étoile, France) and supplemented by analysis of subculture microculture. Initial identification of $C$. albicans by CHROMagar test - Candida ${ }^{\circledR}$ was confirmed by the presence of chlamydoconidia in microculture. 


\section{Statistical analysis}

Continuous variables were compared by using the Student $t$ test for normally distributed variables and the Mann-Whitney U test for nonnormally distributed variables. Differences in proportions were compared by a chi-square test or Fisher's exact test, when appropriate. Mean values \pm 1 standard deviation were reported. Alpha was set equal to 0.05 , and all tests of significance were two tailed. When collinearity was identified between two variables in a correlation matrix, the one with the greatest clinical relevance associated with mortality was included in the multivariate analysis. Odds ratios (ORs) with $95 \%$ confidence intervals (CIs) were calculated for all variables. Variables found to be significant by univariate analysis were then entered into a multivariate model. All statistical analyses were done by using the Statistical Package for the Social Sciences software (SPSS, Inc., Chicago, IL).

\section{Results}

\section{Study population and patient characteristics}

A total of 272 patients with episodes of Candida spp BSIs were identified at Hospital São Paulo during the 7year study period. Of these, 101 patients were excluded; 14 patients were on antifungal therapy when blood samples for culture were obtained, 22 patients because they had polymicrobial BSIs, and 65 due to incomplete data in medical records. Of the remaining 171 patients, 89 had Candida albicans BSI and were further analyzed. The other 82 patients had infection due to non-albicans species.

The mean age of patients with Candida albicans BSI was $62.5 \pm 16.5$ years (range, 18 to 93 years). Fifty-seven patients $(57.3 \%)$ were over 60 years of age. The most frequent diagnoses responsible for hospitalization were gastrointestinal diseases (27.0\%), respiratory diseases (21.4\%), and solid and hematologic malignancies (12.3\%). The most frequent sources of BSIs were central venous catheters (42.7\%) and gastrointestinal (33.7\%). Most BSIs (70.8\%) occurred after 21 days of hospitalization (Table 1).

\section{Time to positivity}

The mean time to positivity was $41.9 \mathrm{~h} \pm 19.2$ hours (range 6.7 to 95.2 hours) for Candida albicans. In approximately half of the cases (56.2\%) growth of Candida albicans occurred within 36 hours. We therefore divided the cases into two groups: patients with an early time to positivity (TTP of $\leq 36 \mathrm{~h}$ ) and patients with a late time to positivity (TTP of $>36 \mathrm{~h}$ ). Associated risk factors and outcomes of the two TTP groups are summarized in Table 2.

Neoplasia was more commonly associated with a BSI TTP of $\leq 36 \mathrm{~h}$ than with a TTP of $>36(41.0 \%$ and $20.0 \%$, respectively; $P=0.030$ ). Blood transfusion was also more
Table 1 Demographic characteristics of 89 patients with C. albicans BSI

\begin{tabular}{|c|c|c|}
\hline Variables & $\mathrm{N}$ & $\%$ \\
\hline \multicolumn{3}{|l|}{ Gender } \\
\hline Male & 54 & 60.7 \\
\hline Female & 35 & 39.3 \\
\hline \multicolumn{3}{|l|}{ Age (years) } \\
\hline$<60$ & 38 & 42.7 \\
\hline$\geq 60$ & 51 & 57.3 \\
\hline $\mathrm{ICU}$ & 20 & 22.5 \\
\hline \multicolumn{3}{|l|}{ Diagnosis on admission } \\
\hline Gastrointestinal disease & 24 & 27.0 \\
\hline Respiratory disease & 19 & 21.4 \\
\hline Neoplasm & 11 & 12.3 \\
\hline Neurologic disease & 6 & 6.8 \\
\hline Cardiovascular disease & 5 & 5.6 \\
\hline Trauma & 4 & 4.5 \\
\hline Renal failure & 4 & 4.5 \\
\hline AIDS & 2 & 2.2 \\
\hline Other & 14 & 15.7 \\
\hline \multicolumn{3}{|l|}{ Site of infection } \\
\hline Catheter & 38 & 42.7 \\
\hline Abdominal & 30 & 33.7 \\
\hline Respiratory & 9 & 10.1 \\
\hline Urinary & 8 & 9.0 \\
\hline Other & 4 & 4.5 \\
\hline \multicolumn{3}{|c|}{ Hospital stay prior to BSI (days) } \\
\hline$\leq 2^{*}$ & 1 & 1.1 \\
\hline $3-7$ & 4 & 4.5 \\
\hline $8-14$ & 11 & 12.3 \\
\hline $15-21$ & 10 & 11.3 \\
\hline$>21$ & 63 & 70.8 \\
\hline \multicolumn{3}{|l|}{ Time to positivity } \\
\hline$\leq 24$ hs & 16 & 18.0 \\
\hline$>24--\leq 36$ hs & 23 & 25.8 \\
\hline$>36-\leq 48$ hs & 20 & 22.5 \\
\hline$>48 \mathrm{hs}$ & 30 & 33.7 \\
\hline \multicolumn{3}{|c|}{ Receiving adequate antifungal therapy } \\
\hline No & 69 & 77.5 \\
\hline Yes & 20 & 22.5 \\
\hline
\end{tabular}

commonly associated with a BSI TTP of $\leq 36 \mathrm{~h}(53.8 .0 \%$ vs. $30.0 \% ; P=0.023)$. Central venous catheters were more commonly associated with a BSI TTP of $\leq 36 \mathrm{~h}$ (56.4\% vs. $32.0 \% ; P<0.04$ ). There was also a statistically significant difference in the proportion of patients with gastrointestinal sources of BSIs between the two groups 
Table 2 Univariate analysis of factors associated with time to positivity in C. albicans BSIs

\begin{tabular}{|c|c|c|c|c|c|}
\hline \multirow[t]{2}{*}{ Variables } & \multicolumn{2}{|c|}{ Time to positivity $\leq 36$ hs $(n=39)$} & \multicolumn{2}{|c|}{ Time to positivity $>36$ hs $(n=50)$} & \multirow[t]{2}{*}{$\mathbf{P}$} \\
\hline & $\mathrm{N}$ & $\%$ & $\mathrm{~N}$ & $\%$ & \\
\hline \multicolumn{6}{|l|}{ Demographic characteristics } \\
\hline Age, mean years $\pm S D$ & $58.4 \pm 17.8$ & & $65.6 \pm 14.8$ & & 0.04 \\
\hline Male & 25 & 64.1 & 29 & 58.0 & 0.56 \\
\hline \multicolumn{6}{|l|}{ Underlying conditions } \\
\hline Charlson $\geq 3$ & 23 & 59.0 & 26 & 52.0 & 0.51 \\
\hline Rapidly fatal disease (MacCabe) & 26 & 66.7 & 28 & 56.0 & 0.31 \\
\hline Diabetes & 6 & 15.4 & 13 & 26.0 & 0.23 \\
\hline Neoplasia & 16 & 41.0 & 10 & 20.0 & 0.03 \\
\hline Neutropenia & 1 & 2.6 & 2 & 4.0 & 0.44 \\
\hline Surgery & 24 & 61.5 & 26 & 52.0 & 0.34 \\
\hline Blood transfusion & 21 & 53.8 & 15 & 30.0 & 0.02 \\
\hline \multicolumn{6}{|c|}{ Conditions related to the clinical course } \\
\hline APACHE II score $\geq 20$ at BSI onset & 11 & 28.2 & 23 & 46.0 & 0.09 \\
\hline Adequate antifungal therapy & 13 & 33.3 & 7 & 14.0 & 0.03 \\
\hline \multicolumn{6}{|l|}{ Source of infection } \\
\hline Intravascular catheter & 22 & 56.4 & 16 & 32.0 & 0.04 \\
\hline Gastrointestinal & 7 & 17.9 & 23 & 46.0 & 0.01 \\
\hline Respiratory tract & 5 & 12.8 & 4 & 8.0 & 0.45 \\
\hline Urinary tract & 3 & 7.7 & 5 & 10.0 & 0.71 \\
\hline Other & 2 & 5.2 & 2 & 4.0 & 0.83 \\
\hline \multicolumn{6}{|l|}{ Outcomes } \\
\hline Organ failure & 31 & 79.5 & 38 & 76.0 & 0.70 \\
\hline Septic shock & 18 & 46.2 & 20 & 40.0 & 0.56 \\
\hline Respiratory failure & 26 & 66.7 & 36 & 72.0 & 0.59 \\
\hline Renal failure & 15 & 38.5 & 18 & 36.0 & 0.81 \\
\hline Hematologic failure & 1 & 2.6 & 4 & 8.0 & 0.26 \\
\hline Hepatic failure & 3 & 7.7 & 5 & 10.0 & 0.71 \\
\hline In-hospital mortality & 29 & 74.4 & 41 & 82.0 & 0.38 \\
\hline
\end{tabular}

(17.9\% in the early group vs. $46.0 \%$ in the late group, $P=0.01$, respectively). Patients with early positive cultures were more likely to have received adequate antifungal therapy $(33.3 \%$ vs. $14.0 \% ; P=0.03)$.

\section{Clinical course}

No statistically significant differences were observed in organ dysfunction and in-hospital mortality between the two groups (Table 2). There was a trend for patients with late positivity to have an APACHE II score $\geq 20$ at BSI onset (46.0\% vs. $28.2 \%$; $P=0.09$ ) (Table 2).

Univarate analysis revealed that APACHE II score $\geq 20$ at BSI onset, the development of at least one organ system failure (respiratory, cardiovascular, renal, hematologic, or hepatic), SOFA at BSI onset, SAPS II at BSI onset, and time to positivity were associated with death (Table 3). Age, gender, inadequate antifungal therapy, Charlson score of $\geq 3$, and neoplasia were not significant predictors of mortality on univariate analysis.

Using logistic regression analysis, the only independent predictor of death was time to positivity $(1.04 ; 95 \% \mathrm{CI}$, 1.0-1.1), with mortality increasing $4.0 \%$ per hour prior to culture positivity (Table 3 ). A second model including inadequate antifungal therapy still showed that time to positivity was the only independent predictor of death (1.03; 95\% CI 1.0-1.07).

\section{Discussion}

Recently it has been shown that shorter time to blood cultures positivity in automated systems has been associated 
Table 3 Risk factors for hospital mortality in patients with C. albicans BSI

\begin{tabular}{|c|c|c|c|c|c|c|c|c|}
\hline \multirow[t]{2}{*}{ Variables } & \multicolumn{2}{|c|}{ Died $(n=70)$} & \multicolumn{2}{|c|}{ Recovered $(n=19)$} & \multicolumn{2}{|c|}{ Univariate analysis } & \multicolumn{2}{|c|}{ Multivariate analysis } \\
\hline & $\mathrm{N}$ & $\%$ & $\mathrm{~N}$ & $\%$ & OR & $\mathrm{Cl} 95 \%$ & OR & $\mathrm{Cl} 95 \%$ \\
\hline Age $>60$ years & 43 & 61.4 & 8 & 42.0 & 2.2 & $0.78-6.13$ & & \\
\hline Male gender & 45 & 64.3 & 9 & 47.4 & 0.5 & $0.18-1.39$ & & \\
\hline APACHE II score $\geq 20$ at BSI onset & 32 & 45.7 & 2 & 10.5 & 7.2 & $1.54-33.35$ & 2.1 & $0.3-12.8$ \\
\hline Organ failure (at least one) & 59 & 84.2 & 10 & 52.5 & 4.8 & $1.60-14.60$ & 2.9 & $0.6-13.2$ \\
\hline Respiratory failure & 54 & 77.1 & 8 & 42.1 & 4.6 & $1.60-13.50$ & & \\
\hline Cardiovascular failure & 35 & 50.0 & 3 & 15.8 & 5.3 & $1.43-19.95$ & & \\
\hline Renal failure & 29 & 41.4 & 4 & 21.0 & 2.7 & $0.80-8.82$ & & \\
\hline Hematologic failure & 5 & 7.1 & - & - & 1.3 & $1.15-1.45$ & & \\
\hline Hepatic failure & 8 & 11.4 & - & - & 1.3 & $1.16-1.47$ & & \\
\hline Inadequate antifungal therapy & 55 & 78.6 & 14 & 73.7 & 1.31 & $0.41-4.22$ & & \\
\hline Charlson score $\geq 3$ & 40 & 57.1 & 9 & 47.3 & 1.5 & $0.54-4.10$ & & \\
\hline Neoplasia & 20 & 28.5 & 6 & 31.5 & 0.9 & $0.29-2.60$ & & \\
\hline SOFA at BSI onset, mean $( \pm S D)$ & \multicolumn{2}{|c|}{$6.7(4.3)$} & \multicolumn{2}{|c|}{$3.6(2.3)$} & 1.28 & $1.07-1.52$ & 1.05 & $0.8-1.3$ \\
\hline SAPS II at BSI onset, mean ( \pm SD) & \multicolumn{2}{|c|}{$48.4(15.4)$} & \multicolumn{2}{|c|}{$35.2(14.3)$} & 1.06 & $1.02-1.11$ & 1.04 & $0.9-1.1$ \\
\hline Time to positivity (in hours), mean ( \pm SD) & \multicolumn{2}{|c|}{$43.9(19.8)$} & \multicolumn{2}{|c|}{$34.6(15.4)$} & 1.03 & $1.0-1.06$ & 1.04 & $1.0-1.1$ \\
\hline
\end{tabular}

with worse prognosis in infections caused by bacteria (i.e., shorter times are associated with higher mortality) [9-11]. This has been shown for S. aureus [9], Streptococcus pneumoniae [11] and Escherichia coli BSI [10]. These findings prompted us to study the time to positivity of candidemia (C. albicans), since the studies analyzing time of positive Candida spp culture are rare and almost all were performed in vitro [19-21].

In our study, only the time to blood culture positivity was predictive of mortality for Candida albicans. The severity of illness (APACHE II, SAPS II and SOFA) was not significantly different between the two groups.

We identified in the medical literature only three clinical studies that analyzed the time to positivity for candidemia, but these had different goals: comparing the differential time to positivity between specimens obtained peripherally and via a central venous catheter [22]; quantifying the time between the collection of blood culture and its positivity [8]; and evaluating the time to positivity for detecting Candida species resistant to fluconazole [23].

Regarding Candida albicans BSI, our study showed the longer the time to positivity, the higher the mortality. We found only one report with a similar finding and this was for Staphylococcus aureus bacteremia [24]. In this retrospective study they observed that a shorter time to positivity was associated with methicillin susceptibility and an endovascular source; multivariate analysis showed higher mortality both with time to positivity $\leq 12$ or $>48$ hours [24].
Physicians often wait for the blood cultures to grow Candida prior to beginning antifungal therapy. However, even if the patient has a stable clinical condition and not receiving empirical antifungal treatment, this may be associated with a poor outcome.

Until the early 2000s, the vast majority of candidemia cases were diagnosed in intensive care units [3,25]. Recent studies have shown a decrease in the proportion of Candida BSIs occurring in ICUs, especially in Latin America countries, with a fall between the years 2008 and 2009 from $64.9 \%$ to $42.6 \%$ [26].

We observed that only $22.5 \%$ of patients with candidemia (C. albicans) received adequate antifungal therapy in the first 24 hours after the suspected infection or collection of blood cultures. Although the reason for not instituting empiric treatment was not evaluated, we believe it has occurred at least in part, due to the delay in blood culture positivity. Other studies have also found that candidemia has one of the highest rates of inadequate empirical treatment in the first 24 hours after suspected infection [6,7].

A multicenter study reported that the mean time for initiating empiric antifungal therapy was 3.8 days [3]. These data emphasize the need to consider early initiation of empiric therapy given that blood cultures are slow to turn positive for Candida species.

Comparing the mean time to positivity for Candida albicans with other studies, we found that the automated BacT/ALERT ${ }^{\circledR}$ time growth is faster $[8,27]$. Lai and colleagues (2012) reported similar time using the BACTEC ${ }^{\circledR}$ system [23]. It should be noted that in our study we did 
not use specific culture medium for fungi. However another study also used specific culture medium for fungi (BACTECTM Myco/F Lytic) whose time to positivity is known to be shorter, especially in the identification of non-albicans Candida species. They showed differences between the mean time to positivity for Candida albicans between the specific culture medium for fungi versus a non-specific medium for fungi (aerobic culture), $34 \pm 25 \mathrm{~h}$ vs. $42 \pm 19$ h, respectively [23].

Our study is limited by the retrospective nature of our analysis. In addition, because of the relatively small sample size of our study $(n=89)$, a type II error could have occurred, which would limit the ability to detect a statistically significant difference in the other variables considered as predictors of mortality.

\section{Conclusions}

The present study showed that the time to positivity for Candida albicans BSI is associated with a significantly greater risk for mortality. These data suggest that physicians should consider empiric antifungal therapy in patients with risk factors for candidemia rather than waiting for the growth of Candida albicans in culture.

\section{Competing interests}

The authors have declared that no competing interests exist.

\section{Authors' contributions}

CZN, ARM, and ESV participated in the data collected and data analysis. ARM MBE and CAPP participated in the design and coordination. CZN, ARM, MBE, ESV and CAPP helped to draft the manuscript and to provide critical review of the manuscript. All authors read and approved the final manuscript.

\section{Funding}

No external funding was received for this work.

\section{Author details}

${ }^{1}$ Infectious Diseases Division, Universidade Federal de São Paulo (UNIFESP), São Paulo, Brazil. ${ }^{2}$ Division of Medical Practice, Hospital Israelita Albert Einstein, São Paulo, Brazil. ${ }^{3}$ Department of Internal Medicine, Virginia Commonwealth, University School of Medicine, Richmond, Virginia, USA.

Received: 2 February 2013 Accepted: 17 October 2013

Published: 20 October 2013

\section{References}

1. Wisplinghoff H, Bischoff $T$, Tallent SM, Seifert H, Wenzel RP, Edmond MB: Nosocomial bloodstream infections in US hospitals: analysis of 24.179 cases from prospective nationwide surveillance study. Clin Infect Dis 2004, 39:309-317.

2. Brazilian SCOPE Study Group, Marra AR, Camargo LF, Pignatari AC, Sukiennik T, Behar PR, Medeiros EA, Ribeiro J, Girao E, Correa L, Guerra C, Brites C, Pereira CA, Carneiro I, Reis M, de Souza MA, Tranchesi R, Barata CU, Edmond MB: Nosocomial bloodstream infections in Brazilian hospitals: analysis of 2,563 cases from a prospective nationwide surveillance study. J Clin Microbiol 2011, 49:1866-1871

3. Colombo AL, Guimarães T: Silva LR, de Almeida Monfardini LP, Cunha AK, Rady P, Alves T, Rosas RC: Prospective observational study of candidemia in São Paulo, Brazil: incidence rate, epidemiology, and predictors of mortality. Infect Control Hosp Epidemiol 2007, 28:570-576.

4. Geha DJ, Roberts GD: Laboratory detection of fungemia. Clin Lab Med 1994, 14:83-97.

5. Pappas PG: Invasive candidiasis. Infect Dis Clin N Am 2006, 20:485-506.
6. Pappas PG, Kauffman CA, Andes D, Benjamin DK Jr, Calandra TF, Edwards JE, Filler SG, Fisher JF, Kullberg BJ, Ostrosky-Zeichner L, Reboli AC, Rex JH, Walsh TJ, Sobel JD: Infectious Diseases Society of America: Clinical Practice Guidelines for the Management of Candidiasis: 2009 Update by the Infectious Diseases Society of America. Clin Infect Dis 2009, 48:503-535.

7. Ibrahim EH, Sherman G, Ward S, Fraser VJ, Kollef MH: The influence of inadequate antimicrobial treatment of bloodstream infections on patient outcomes in the ICU setting. Chest 2000, 118:146-155.

8. Fernandez J, Erstad BL, Petty W, Nix DE: Time to positive culture and identification for Candida bloodstream infections. Diagn Microbiol Infect Dis 2009, 64:402-407.

9. Marra AR, Edmond MB, Forbes BA, Wenzel RP, Bearman GM: Time to blood culture positivity as a predictor of clinical outcome of Staphylococcus aureus bloodstream infection. J Clin Microbiol 2006, 44:1342-1346.

10. Martínez JA, Soto S, Fabrega A, Almela M, Mensa J, Soriano A, Marco F, Jimenez de Anta MT, Vila J: Relationship of phylogenetic background, biofilm production, and time to detection of growth in blood culture vials with clinical variables and prognosis associated with Escherichia coli bacteremia. J Clin Microbiol 2006, 44:1468-1474.

11. Peralta G, Rodríguez-Lera MJ, Garrido JC, Ansorena L, Roiz MP: Time to positivity in blood cultures of adults with Streptococcus pneumoniae bacteremia. BMC Infect Dis 2006, 6:79-86.

12. Charlson ME, Pompei $P$, Ales KL, MacKenzie CR: A new method of classifying prognostic comorbidity in longitudinal studies: development and validation. J Chronic Dis 1987, 40:373-383.

13. Knaus WA, Draper EA, Wagner DP, Zimmerman JE: APACHE II: a severity of disease classification system. Crit Care Med 1985, 13:818-829.

14. Le Gall JR, Lemeshow S, Saulnier F: A new Simplified Acute Physiology Score (SAPS II) based on a European/North American multicenter study. JAMA 1993, 270:2957-2963.

15. Vincent JL, de Mendonca A, Cantraine F, Moreno R, Takala J, Suter PM, Sprung $\mathrm{CL}$, Colardyn F, Blecher S: Use of the SOFA score to assess the incidence of organ dysfunction/failure in intensive care units: results of a multicenter, prospective study. Working group on "sepsis-related problems" of the European Society of Intensive Care Medicine. Crit Care Med 1998, 26:1793-1800

16. American College of Chest Physicians/Society of Critical Care Medicine: Consensus Conference: definitions for sepsis and organ failure and guidelines for the use of innovative therapies in sepsis. Crit Care Med 1992, 20:864-874.

17. Fagon JY, Chastre J, Novara A, Medioni P, Gibert C: Characterization of intensive care unit patients using a model based on the presence or absence of organ dysfunctions and/or infection: the ODIN model. Intensive Care Med 1993, 19:137-144.

18. Garner JS, Jarvis WR, Emori TB, Horan TC, Hughes JM: CDC definitions for nosocomial infections. Am J Infect Control 1988, 6:128-140.

19. Horvath LL, George BJ, Murray CK, Harrison LS, Hospenthal DR: Direct comparison of the BACTEC 9240 and BacT/ALERT 3D automated blood culture systems for Candida growth detection. J Clin Microbiol 2004, 42:115-118.

20. George BJ, Horvath LL, Hospenthal DR: Effect of inoculums size on detection of Candida grow by the BACTEC 9240 automated blood culture system using aerobic and anaerobic media. J Clin Microbio/ 2005, 43:433-435.

21. Maaroufi Y, De Bruyne JM, Duchateau V, Georgala A, Crokaert F: Early detection and identification of commonly encountered Candida species from simulated blood cultures by using a real-time PCR-based assay. J Mol Diagn 2004, 6:108-114.

22. Ben-Ami R, Weinberger M, Orni-Wasserlauff R, Schwartz D, Itzhaki A, Lazarovitch T, Bash E, Aharoni Y, Moroz I, Giladi M: Time to blood culture positivity as a marker for catheter-related candidemia. J Clin Microbiol 2008, 46:2222-2226.

23. Lai CC, Wong CY, Liu WL, Huang YT, Hsueh PR: Time to positivity of blood culture of different Candida species causing fungaemia. J Med Microbiol 2012, 61:701-704.

24. Kim J, Gregson DB, Ross T, Lauplant KB: Time to blood culture positivity in Staphylococcus aureus bacteremia: association with 30-day mortality. J Infect 2010, 61:197-204.

25. Blot SI, Vandewoude KH, Hoste EA, Colardyn FA: Effects of nosocomial candidemia on outcomes of critically ill patients. Am J Med 2002, 113:480-485. 
26. Pfaller MA, Messer SA, Moet GJ, Jones RN, Castanheira M: Candida bloodstream infections: comparison of species distribution and resistance to echinocandin and azole antifungal agents in Intensive Care Unit (ICU) and non-ICU settings in the SENTRY Antimicrobial Surveillance Program (2008-2009). Int J Antimicrob Agents 2011, 38:65-69.

27. Jorgensen JH, Mirrett S, McDonald LC, Murray PR, Weinstein MP, Fune J, Trippy CW, Marsterson M, Reller LB: Controlled clinical laboratory comparison of BACTEC Plus Aerobic/F resin medium with BacT/Alert Aerobic FAN medium for detection of bacteremia and fungemia. J Clin Microbiol 1997, 35:53-58.

doi:10.1186/1471-2334-13-486

Cite this article as: Nunes et al:: Time to blood culture positivity as a

predictor of clinical outcome in patients with Candida albicans

bloodstream infection. BMC Infectious Diseases 2013 13:486.

\section{Submit your next manuscript to BioMed Central and take full advantage of:}

- Convenient online submission

- Thorough peer review

- No space constraints or color figure charges

- Immediate publication on acceptance

- Inclusion in PubMed, CAS, Scopus and Google Scholar

- Research which is freely available for redistribution 